\title{
Physico-Chemical Analysis and Polarization Value Estimation of Raw Sugar from Refining Point of View
}

\author{
Zia-ud-Din*, Ghulam Rasool \\ National Institute of Food Science and Technology, University of Agriculture, Faisalabad, Pakistan \\ Email: "
}

Received 26 November 2014; revised 14 December 2014; accepted 5 January 2015

Copyright (C) 2015 by authors and Scientific Research Publishing Inc.

This work is licensed under the Creative Commons Attribution International License (CC BY). http://creativecommons.org/licenses/by/4.0/

(c) (i) Open Access

\section{Abstract}

This study was particularly designed to evaluate the physico-chemical parameters and polarization value of raw sugar which ultimately affect the filterability of raw sugar. Six different raw sugar samples were collected from the local industries and were evaluated for the physico-chemical and polarization value. The physico-chemical characteristics of sugar including moisture, reducing sugar, ash contents, size of crystals and color constituents were assessed. The results obtained from physico-chemical analysis showed that these parameters were affected significantly among the samples of raw sugar. The ash contents were found to be decreasing for the samples in the order of T6 > T1T2T5 > T3T4. The values for the polarization were significantly the highest in sample T5, T2 and T1 followed by sample T4 and T6 while the lowest values were recorded for sample T3. It can be concluded from the results that sample T4 was observed to have a good quality while sample T6 had the opposite result to that of sample T4 and was considered to have a very low quality.

\section{Keywords}

Raw Sugar, Filterability, Physico-Chemical Analysis and Polarization Value

\section{Introduction}

Raw sugar is an intermediate product of refining and affination process of sugar manufacturing that consists of pale yellow to brown sugar crystals covered with a film of syrup. This is in fact, an intermediate stage in the production of sugar, having sucrose and water contents $95 \%-97 \%$ and $0.25 \%-1.1 \%$, respectively. It is of yel-

\footnotetext{
${ }^{*}$ Corresponding author.
}

How to cite this paper: Zia-ud-Din and Rasool, G. (2015) Physico-Chemical Analysis and Polarization Value Estimation of Raw Sugar from Refining Point of View. American Journal of Plant Sciences, 6, 1-5. 
lowish brown color due to the presence of molasses (3.6\%) and has burnt flavor with coarse crystal [1].

The sugarcane (Saccharum officinarum L.) is a commonly distributed plant and is one of the most significant sources of sugar in Pakistan. Current reports have shed light on numerous biological properties of sugarcane and its resulting products. Fresh sugarcane juice is widespread in Pakistan as an inexpensive and sweet beverage. It is becoming a fashion juice and thirst satisfying drink served at roadside stalls, canteens and cafeterias throughout the country during the harvest season [2].

Sugarcane is grown in Kharif season and is one of the main cash crops of Pakistan. It delivers raw material to sugar industries and sugar associated products. For the rural community of the country, it produces income and services. Vital items for industries like sugar, chipboard and paper, sugarcane help in their value addition. Its share is 3.6 percent in agriculture and 0.8 percent in GDP. For the year 2009-10, an area of 943 thousand hectares is under sugarcane cultivation which is 8.4 percent less as compared to the previous year (1029 thousand hectares). Production of the sugarcane for the year 2009-10 is assessed to be 49.4 million tons, in contrast to 50 million tons previous year; ultimately the production is reduced to 1.3 percent. Key factors involved for low productions were canal water scarcity, electricity shortage; area under wheat crop during 2008-09 was maximum ultimately confining the sugarcane acreage. Lower prices for the sugarcane crop in the previous year and higher inputs rates also restricted the farming community from growing sugarcane crop [3].

The keeping quality of sugar was studied keeping in the view that the process of drying played a pivotal role. By keeping the sugar under humid conditions, microbial decomposition along with loss of sugar occurred rendering the quality of sugar impure. After the process of drying, the process of polarization becomes augmented and the notorious effects of microorganisms become less. If the sugar is wet when fed into the dryer, a large amount of heat is required for the process of drying the sugar. Sample purity plays a vital role in determination of overall moisture contents of the sugar sample. If the size of the crystals of sugar becomes enlarged, it will ultimately increase the moisture percentage of the sugar sample [1].

\section{Materials and Methods}

Samples of raw sugar were procured from sugarcane industry/local market. The research was conducted at the National Institute of Food Science and Technology in University of Agriculture Faisalabad.

\subsection{Moisture Content}

Moisture was determined by taking $10 \mathrm{~g}$ of sample and drying it in a hot air oven at $100^{\circ} \mathrm{C}+5^{\circ} \mathrm{C}$ for about 3 hours as recommended by [4]. The loss in weight was the moisture contents calculated by using the following formula:

$$
\% \text { Moisture content }=\frac{\text { loss of weight during drying }}{\text { Weight of sample }} \times 100
$$

\subsection{Ash Content}

Total ash contents were determined as described in [5] by taking 5 gram sample in the china dish and placed on low flame while the mass is thoroughly charred, then the sample was heated in muffle furnace at $500^{\circ} \mathrm{C}+50^{\circ} \mathrm{C}$ until white ash was obtained. This ash was cooled in the desiccator and weighed in percentage using the following formula:

$$
\% \text { Total ash }=\frac{\text { Weight of ash }}{\text { Weight of sample }} \times 100
$$

\subsection{Color Analysis}

Color analysis was determined as outlined in [5] by using color meter (Nauhaus color test-II, Neotec). It was first calibrated with the standards having lower and upper limits (51 - 70 respectively). Then the samples were filled in the petri plates and the surface was made smooth by removing the sample material from the petri plates, to get the optimum reflection of light, emerged by the photo cells of the color meter and the reading was noted from the display. Sample readings were compared with the standards. 


\subsection{Grain Size of Crystals}

Grain size crystal was determined according to standard procedures of [5]. According to SI specifications, crystals were graded into five sizes. In the grain size analysis, $100 \mathrm{~g}$ of sugar was taken on sieves, placed on a nest of sieves with a lid on the top of sieve and received at the bottom and was shaken for five minutes on a mechanical sieve shaker. The weight of each sample in gram was taken in the percentage of the sugar retained in the particular sieve. From the values, the accumulative percentage is calculated and compared.

\subsection{Reducing Sugars}

Reducing sugars were estimated by following the procedure as described in [5]. Standard solutions and samples were prepared by using the required reagents and contents of reducing sugars were determined by using the following formula:

$$
\begin{gathered}
\text { Reducing sugars }(A)=\mathrm{mg} / 100 \mathrm{ml}=\frac{(\text { Factor }) *(100)(\text { dilution })}{25 * \text { Titer Value }} \\
\text { Total sugars }(B)=\mathrm{mg} / 100 \mathrm{ml}=\frac{(\text { Factor }) *(100) *(250)(\text { dilution })}{25 * 50 * \text { Titer Value }} \\
\text { Non reducing sugars }=(B-A) * 0.95=C \\
\text { Total sugars }=A+C
\end{gathered}
$$

\subsection{Polarization Value}

Polarization value was determined using the procedures as described in [5] by using polarimeter or polariscope and for this method $26 \mathrm{~g}$ raw sugar sample was taken to $100 \mathrm{ml}$ volumetric flask. Then $70 \mathrm{ml}$ water was added and was shaken until all the crystals were dissolved. The clarification of the solution was done using $3 \mathrm{ml}$ of $54.30^{\circ}$ brix lead acetate solution. Then the volume was made $100 \mathrm{ml}$ and filtered. Using the $200 \mathrm{~mm}$ tube of the polarimeter, the pol value was determined. The polarization for temperature was corrected by the following formula:

$$
P 20=P t+0.0015(P t-80)(t-20)
$$

where

$t=$ temperature of polarization and

$P t=$ polarization reading at temperature $t$.

\subsection{Statistical Analysis}

The collected data was analyzed by using completely randomized design (CRD) and analysis of variance technique. Duncan's New Multiple Range (DNMR) test at 5\% probability was applied to compare the significance among the treatments means [6].

\section{Results and Discussion}

\subsection{Moisture Content}

The statistical data narrated that the moisture contents of several raw sugar samples were affected highly significant. The values for the mean of the moisture contents for various raw sugar samples are shown in Table 1. It had been determined by [1] that the moisture contents of the raw sugar were 40 percent during the examination.

The moisture contents of the different raw sugar samples were in the range of 0.20 to 0.76 percent. The data also showed that the highest moisture contents were found in sample T6 followed by sample T1 while lowest values were recorded for sample T4. The moisture contents of the sugar is adaptable because of the non-reducing sugars during the process of manufacturing and also because of the contribution of the different types of agronomic factors such as storage, moisture, type of irrigation, soil conditions, season of harvesting and variety of cane crop [7]. Such factors are involved during the analysis and study of present research. So the present difference can be attributed to these factors. 
Table 1. Mean values for moisture content, ash content, color analysis, grain size of crystal, reducing sugars and polarization value.

\begin{tabular}{|c|c|c|c|c|c|c|}
\hline Treatments & $\begin{array}{c}\text { Moisture } \\
\text { Content (\%) }\end{array}$ & $\begin{array}{c}\text { Ash } \\
\text { Content (\%) }\end{array}$ & $\begin{array}{c}\text { Color } \\
\text { Analysis (CTN) }\end{array}$ & $\begin{array}{c}\text { Grain Size } \\
\text { of Crystal (mm) }\end{array}$ & $\begin{array}{l}\text { Reducing } \\
\text { Sugars (\%) }\end{array}$ & $\begin{array}{l}\text { Polarization } \\
\text { Value ( }\left(^{\circ}\right)\end{array}$ \\
\hline T1 & 0.5333ab & $0.5333 \mathrm{ab}$ & 418.33c & $0.4067 \mathrm{c}$ & $0.17 \mathrm{bc}$ & 99.033a \\
\hline $\mathbf{T} 2$ & $0.4000 \mathrm{bc}$ & $0.3000 \mathrm{ab}$ & 422.33bc & $0.3933 c$ & $0.16 \mathrm{bc}$ & 99.130a \\
\hline T3 & $0.2333 c$ & $0.1667 \mathrm{~b}$ & $420.00 c$ & $0.5600 \mathrm{a}$ & $0.14 \mathrm{c}$ & 97.757b \\
\hline T4 & $0.2000 c$ & $0.1333 b$ & 447.00abc & $0.5867 a$ & $0.14 \mathrm{c}$ & 98.507ab \\
\hline T5 & $0.3000 \mathrm{bc}$ & $0.3000 \mathrm{ab}$ & 490.67ab & $0.4667 b$ & $0.23 a b$ & 99.423a \\
\hline T6 & $0.7667 a$ & $0.7333 a$ & 503.33a & $0.4733 b$ & $0.25 a$ & 98.693ab \\
\hline
\end{tabular}

\subsection{Ash Content}

It is shown by the data that the values are affected highly significant for the ash contents in the samples of raw sugar. The mean values for the ash contents are shown in Table 1. It can be established from the data presented in the table that the highest value for the ash contents was found for sample T6 which was 0.73 percent while the lowest value was recorded for the samples $\mathrm{T} 1, \mathrm{~T} 2$ and $\mathrm{T} 5$. So the values for the ash contents were found to be decreasing for the samples in the order of T6 $>$ T1T2T5 $>$ T3T4 while it had been established by many sugar technologists that the contents of ash in the samples of sugar should not exceed 0.5 percent. These results were reviewed and after doing further analysis he determined that the ash contents in some of the raw sugar were in high concentration because the raw sugar was affined for purification at different temperatures for the quality improvement [8].

\subsection{Color Analysis}

The results showed that the color values were affected highly significant among the samples of raw sugar. The mean values for the color contents in different raw sugar samples are shown in Table 1 . The data showed that the maximum color was observed for sample $\mathrm{T} 6$ and lowest was recorded for sample T1. These results are in line with the above mentioned ICUMSA standards. According to ICUMSA (2007) standards, the maximum color range of the raw sugar should be in the range of $400-600$.

It was proposed that some factors played an important role in the determination of color and these factors affect the color of the sugar. Some of these factors include sugar crystal size, color types, ash constituents, boiling time, crystal distribution, polysaccharides and color and purity of pan feed liquor. These factors determine the overall quality of sugar [9]. So it was concluded that the increase value for the color contents in the sample T6 was due to the occurrence of these impurities due to improper affination process or other refining process ultimately making it a low quality raw sugar.

\subsection{Size of Crystals}

The statistical analysis showed that the relationship between different raw sugar samples regarding the size of crystals were affected highly significant. The mean values for size of crystals among raw sugar samples had been presented in Table 1 . The size of crystals for different raw sugar samples were in the range of $0.39-0.58$ $\mathrm{mm}$. The sample T3 and T4 had the maximum size of crystal of 0.56 and $0.58 \mathrm{~mm}$ respectively while the minimum size of crystal was recorded for sample T2 which had a size of $0.39 \mathrm{~mm}$. As the standard size ranges from $0.35-0.60 \mathrm{~mm}$, so all the samples fell in the range of standard values.

It can be concluded from the review that during the sugar production optimal control is required for the growth of crystals in the crystallization stage is a vital factor for the production of sugar crystals that have the size according to specification. The process of growth and size of crystals can be observed by implementing varieties of different methods which involve visual inspections as well as indirect measurements [10].

\subsection{Reducing Sugars}

It can be concluded from the table that the reducing sugar contents was affected highly significant among the 
different raw sugar samples. The mean values for reducing sugar are represented in Table 1 . The data in the table indicated that the concentration of the reducing sugar contents are highest for the sample T6 while lowest values were recorded for sample T3 and T4. It can be concluded from the results mentioned above that the sample T6 was obtained from a cane that was not fully matured and the non-maintenance of the processing temperature might had played a role that ultimately caused the degradation of the monosaccharides. While the low concentration of the reducing sugar contents in the sample T3 and T4 implies that these samples were devised from a cane that was matured fully and treated with appropriate processing temperature causing the monosaccharides destruction that ultimately resulted in good quality cane sugar. It was inspected that the reducing sugar contents were associated with the quantity of sucrose. So regarding their percentage, both have effects on each other [11].

\subsection{Polarization Value}

The statistical data revealed that the values for the polarization were affected significantly by the samples. The mean values for the samples of raw sugar are presented in Table 1 . The data showed that the values for the polarization are significantly highest in sample T5, T2 and T1 followed by sample T4 and T6 while the lowest values were recorded for sample T3. According to ICUMSA (2007) variable factors play a vital role in determining the value of polarization in sugar. The decreasing in the value of polarization was might due to the fluctuation in the processing of raw sugar and also the coloring compounds and the impurities may have an interaction in the determination of this parameter. While for the values that are highest for some samples might be due to the more sucrose contents because raw sugar still needs further processing in order to make it palatable for human consumption.

\section{Conclusion}

Thus, it can be concluded from the present research that the sample T4 is the best regarding the sugar quality and can be recommended to the industry for further processing and affination process. It can also be concluded that such type of sugar should be collected from the fields to serve the consumers while sample from T1 to T3 are also of desire quality and can be recommended to the industry and consumer after processing and quite near to the standards and are collected from the sugarcane industries. On the other hand, sample T6 was collected from the cottage industry. It was proved to be of very poor quality and therefore cannot be recommended to the industry for further processing.

\section{References}

[1] Javaid, G.S., Bhatti, M.B. Rashid, K. and Khalid, M. (2011) To Introduce the Raw Sugar Refinery, Its Operational Concept and Quality Prespective in Pakistan. Life Science International Journal, 5, 2053-2062.

[2] Ali, F.G., Chattha, A.A. and Iqbal, M.A. (2001) Some Fundamental Causes of Low Sugar Recovery and Vital Approach for Its Improvement. Pakistan Sugarcane Journal, 16, 56-61.

[3] GOP (2009-2010) Agricultural Statistics of Pakistan. Ministry of Food, Agriculture and Livestock, Government of Pakistan, Islamabad.

[4] ICUMSA Methods (2007) International Commission for Uniform Methods of Sugar Analysis. 234-241.

[5] AOAC (2000) Official Methods of Analysis. The Association of Official Analytical Chemists, 15th Edition, Arlington.

[6] Steel, R., Torrie, J. and Dickey, D. (1997) Principles and Procedures of Statistics. A Biometrical Approach. 3rd Edition, McGraw Hill Book Co., New York.

[7] Chen, J.C.P. and Chou, C.C. (1993) Cane Sugar Handbook: A Manual for Cane Sugar Manufacturer and Chemists. John Willey and Sons, Inc., New York, 401-403.

[8] Chauhan, M.K., Varun, Chaudhary, S., Kumar, S. and Samar (2011) Life Cycle Assessment of Sugar Industry Review. Renewable Sustainable Energy Reservations, 15, 3445-3453. http://dx.doi.org/10.1016/j.rser.2011.04.033

[9] Gyura, J., Sere, Z., Vatai, G. and Molnar, E.B. (2007) Separation of Non-Sucrose Compounds from the Syrup of Sugar Beet Processing by Ultra and Nano-Filtration Using Polymer Membranes. Desalination, 148, 49-56. http://dx.doi.org/10.1016/S0011-9164(02)00652-5

[10] Argaw, G.A., Alport, M.J. and Malivga, S.B. (2006) Automatic Measurement of Crystal Size Distribution Using Image Processing. Processing South African Sugar Technology Association, 80, 399-411.

[11] Saska, M. (1989) Composition of 1988 Lousiana Final Molasses. Sugar Journal, 30, 13-15. 
Scientific Research Publishing (SCIRP) is one of the largest Open Access journal publishers. It is currently publishing more than 200 open access, online, peer-reviewed journals covering a wide range of academic disciplines. SCIRP serves the worldwide academic communities and contributes to the progress and application of science with its publication.

Other selected journals from SCIRP are listed as below. Submit your manuscript to us via either submit@scirp.org or Online Submission Portal.
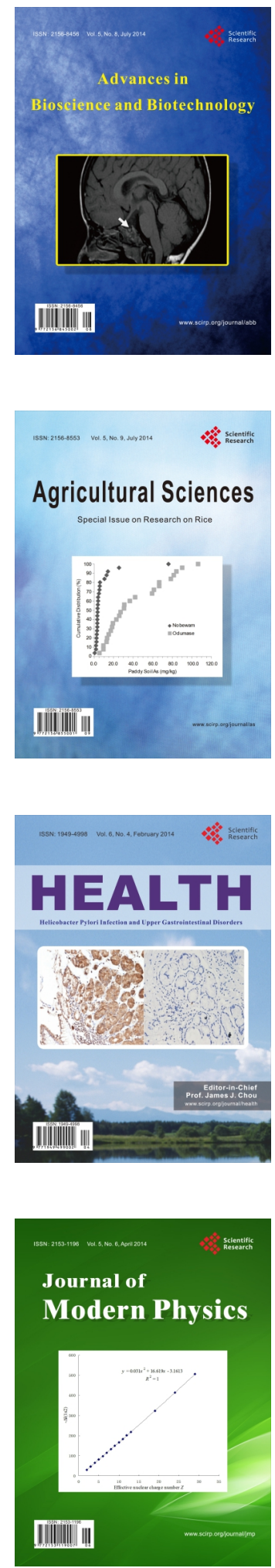
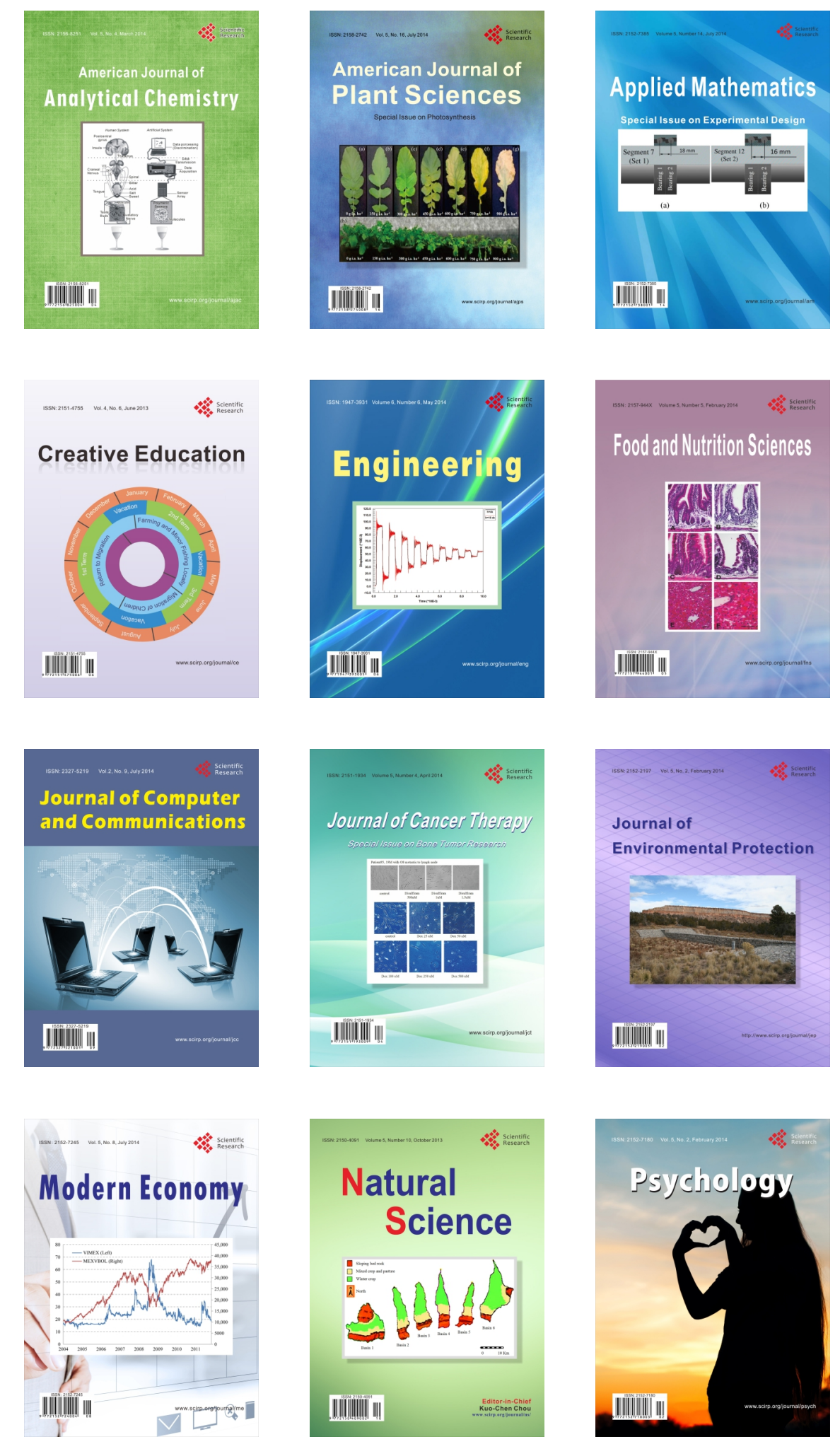